\title{
Regression in left ventricular mass after aortic valve replacement for chronic aortic regurgitation is unrelated to prosthetic valve size
}

\author{
Morgan L. Brown, MD, ${ }^{a}$ Hartzell V. Schaff, MD, ${ }^{b}$ Rakesh M. Suri, MD, ${ }^{b}$ Zhuo Li, MS, ${ }^{c}$ \\ Thoralf M. Sundt, MD, ${ }^{\mathrm{b}}$ Joseph A. Dearani, MD, ${ }^{\mathrm{b}}$ and Maurice Enriquez-Sarano, MD ${ }^{\mathrm{d}}$
}

Objectives: We examined the role of prosthesis-patient mismatch on left ventricular mass regression after aortic valve replacement for chronic aortic valve regurgitation.

\begin{abstract}
Methods: We selected patients who had complete preoperative and follow-up echocardiograms with measurement of left ventricular mass. Patients were excluded who had moderate or greater aortic valve stenosis, concomitant coronary artery bypass grafting, or mitral valve procedures.

Results: Patients' mean age was $55 \pm 17$ years; $21 \%$ were female. The mean preoperative indexed left ventricular mass was $150 \pm 45 \mathrm{~g} / \mathrm{m}^{2}$. Patients with mildly ( $\mathrm{n}=44$; mean indexed mass, $126 \pm 15 \mathrm{~g} / \mathrm{m}^{2}$ ), moderately $\left(\mathrm{n}=31\right.$; mean indexed mass, $\left.168 \pm 11 \mathrm{~g} / \mathrm{m}^{2}\right)$, or severely $\left(\mathrm{n}=15\right.$; mean indexed mass, $\left.241 \pm 34 \mathrm{~g} / \mathrm{m}^{2}\right)$ increased preoperative indexed left ventricular mass, were similar, except for lower ejection fractions, larger end-diastolic dimensions, and larger ventricular wall thicknesses in the severely enlarged group $(P<.001)$. Thirteen patients had prosthesis-patient mismatch and were similar to patients without prosthesis-patient mismatch, except for a greater body surface area, fewer mechanical valves, and smaller valve sizes in those with prosthesis-patient mismatch $(P<.05)$. At a mean follow-up of $3.2 \pm 2.4$ years, the average reduction in indexed left ventricular mass was $50 \pm 38 \mathrm{~g} / \mathrm{m}^{2}$; late mass regression was unrelated to labeled valve size, prosthesis-patient mismatch, or measured indexed effective aortic valve area. A greater preoperative indexed left ventricular mass $(P<.001)$ was an independent predictor of greater left ventricular mass regression. Despite having greater left ventricular mass regression, patients with severe preoperative indexed left ventricular mass did not return to normal values (mean, $142 \pm 25 \mathrm{~g} / \mathrm{m}^{2}$ ).
\end{abstract}

Conclusions: Left ventricular mass regression after aortic valve replacement for chronic aortic regurgitation is unrelated to indexed prosthetic valve area. Although incomplete, regression is greatest in patients with the largest preoperative indexed left ventricular mass. (J Thorac Cardiovasc Surg 2011;142:e5-9)

Prosthesis-patient mismatch (PPM) is a widely known concept after aortic valve replacement (AVR) in which the effective orifice area of the prosthetic valve is small in relation to body size, leaving the patient with residual left ventricular (LV) outflow obstruction. ${ }^{1}$ PPM is believed to be independently associated with mortality after $\mathrm{AVR},{ }^{2-7}$ although some investigators have not found this to be the case. $^{8-12}$ A larger indexed effective orifice area has also been found to be an independent predictor of greater LV mass regression in patients with pure aortic stenosis. ${ }^{6}$ These studies have focused on patients with aortic stenosis.

It is thought that PPM is an infrequent complication in patients undergoing AVR for aortic valve regurgitation

\footnotetext{
From the Department of Anesthesiology and Pain Medicine, ${ }^{a}$ University of Alberta, Edmonton, Alberta, Canada; and Divisions of Cardiovascular Surgery, ${ }^{\mathrm{b}}$ Biostatistics, ${ }^{\mathrm{c}}$ and Cardiovascular Medicine, ${ }^{\mathrm{d}}$ Mayo Clinic, Rochester, Minn.

Disclosures: Authors have nothing to disclose with regard to commercial support.

Received for publication March 14, 2010; revisions received July 27, 2010; accepted for publication Aug 15, 2010; available ahead of print Nov 12, 2010.

Address for reprints: Hartzell V. Schaff, MD, Mayo Clinic, 200 1st St SW, Rochester MN 55905 (E-mail: schaff@mayo.edu).

$0022-5223 / \$ 36.00$

Copyright (C) 2011 by The American Association for Thoracic Surgery doi:10.1016/j.jtcvs.2010.08.043
}

(AR), where the sinus portion of the aorta and the aortic valve annulus are enlarged, permitting implantation of larger valve sizes. The objectives of our study were to determine the degree of LV mass regression in patients who received an aortic valve for AR and to identify predictors of reverse remodeling. Specifically, we were interested in the influence of PPM on regression of LV hypertrophy

\section{METHODS}

After institutional review board approval, we reviewed adult patients (>18 years) who underwent AVR for AR between January 1, 1996, and January 1, 2006. Patients were excluded if they had moderate or greater aortic valve stenosis on preoperative transthoracic echocardiography, which was defined as an aortic valve area of less than $1.5 \mathrm{~cm}$ or a qualitative interpretation of moderate aortic valve stenosis. Also excluded were patients with acute AR owing to aortic dissections or active endocarditis and patients who had prior or concomitant coronary artery bypass grafting and/or mitral valve repair or replacement.

Among 301 eligible patients, we reviewed medical records and selected those who had a preoperative and a follow-up transthoracic echocardiogram available in our echocardiographic database. Echocardiography was performed according to recommendations by the American Society of Echocardiographers. ${ }^{13}$ The echocardiogram must have included measurements of interventricular septal thickness (SWT), posterior wall thickness (PWT), and LV end-diastolic dimensions (LVEDD). These measurements 


\section{Abbreviations and Acronyms}

$\mathrm{AR}=$ aortic valve regurgitation

$\mathrm{AVR}=$ aortic valve replacement

$\mathrm{LV}=$ left ventricular

$\mathrm{LVMi}=$ indexed left ventricular mass

PPM $=$ prosthesis-patient mismatch

are required to calculate the LV mass and indexed LV mass (LVMi). The following formula was used to calculate LVMi:

$$
\left(\left[(\text { SWT }+ \text { PWT }+ \text { LVEDD })^{3}-\left(\text { LVEDD }^{3}\right) * 1.04 * 0.8\right]+0.6\right) / \text { BSA }
$$

where BSA was body surface area.

Patients were divided into those with and without PPM. Mismatch was defined as a measured indexed valve area of less than $0.85 \mathrm{~cm}^{2} / \mathrm{m}^{2}$ on predismissal transthoracic echocardiography. Patients were also divided into terciles of preoperative LVMi: mildly (LVMi $<150 \mathrm{~g} / \mathrm{m}^{2}$ ), moderately (LVMi 150-200 g/m $\mathrm{m}^{2}$ ), and severely increased $\left(\mathrm{LVMi}>200 \mathrm{~g} / \mathrm{m}^{2}\right.$ ). The outcome of this study was defined as the change in LVMi at follow-up from the LVMi recorded before AVR.

Statistical analyses were performed using SAS (version 9.1; SAS Institute, Inc, Cary, Ind). Data are presented as means and standard deviations or numbers and percentages, as appropriate. Univariate analyses between groups were compared using $\chi^{2}$ tests or Fisher's tests for categorical variables and $t$ tests, 1-way analysis of variance tests, or Kruskal-Wallis tests as appropriate. Univariate and stepwise multivariate models were created using linear regression for continuous outcomes and logistic regression for dichotomous outcomes.

\section{RESULTS}

Ninety patients met entry criteria for the study (Table 1). At operation, the median valve size was $25 \mathrm{~mm}$ and 65 patients $(72 \%)$ received a bioprosthesis. Thirteen $(14 \%)$ patients had PPM. When patients were categorized into presence or absence of PPM, there were few differences in preoperative characteristics aside from greater body surface area in patients who had PPM $\left(2.3 \mathrm{~m}^{2}\right.$ vs $2.0 \mathrm{~m}^{2}$;
$P=.002)$. We then examined differences between patients divided into terciles of preoperative LVMi: mild $(n=44$; mean LVMi, $\left.126 \pm 15 \mathrm{~g} / \mathrm{m}^{2}\right)$, moderate $(\mathrm{n}=31$; mean LVMi, $\left.168 \pm 11 \mathrm{~g} / \mathrm{m}^{2}\right)$, or severe $(\mathrm{n}=15$; mean LVMI, $241 \pm 34 \mathrm{~g} / \mathrm{m}^{2}$ ). These groups were similar except for higher ejection fractions and smaller LV end-diastolic dimensions, septal wall thicknesses, and posterior wall thicknesses in the mild group $(P<.001)$ (Table 1$)$. Operative details are given in Table 2.

From predismissal echocardiography, the calculated mean indexed aortic valve area for the entire cohort was $1.1 \pm 0.7 \mathrm{~cm}^{2} / \mathrm{m}^{2}$ and the mean gradient across the aortic valve was $16 \pm 6 \mathrm{~mm} \mathrm{Hg}$. The calculated mean indexed aortic valve area was $0.7 \pm 0.1$ in patients with PPM and $1.2 \pm$ 0.3 in patients without PPM $(P<.001)$, and the mean gradient across the aortic valve was $24 \pm 6 \mathrm{~mm} \mathrm{Hg}$ in patients with mismatch and $15 \pm 5 \mathrm{~mm} \mathrm{Hg}$ in patients without mismatch $(P<.001)$. The mean indexed aortic valve area was found to be $1.1 \pm 0.3 \mathrm{~cm}^{2} / \mathrm{m}^{2}$ in the group with mildly increased LVMi, $1.2 \pm 0.4 \mathrm{~cm}^{2} / \mathrm{m}^{2}$ in the moderately increased group, and $1.2 \pm 0.2 \mathrm{~cm}^{2} / \mathrm{m}^{2}$ in the group with severely enlarged $\operatorname{LVMi}(P=.864)$. The mean gradient across the aortic valve was $17 \pm 7 \mathrm{~mm} \mathrm{Hg}$ in the mild group, $16 \pm 6$ $\mathrm{mm} \mathrm{Hg}$ in the moderate group, and $15 \pm 5 \mathrm{~mm} \mathrm{Hg}$ in the severe group $(P=.496)$.

At a mean follow-up of $3.2 \pm 2.4$ years (median, 2.7 ; interquartile range, 1.1-5.0 years), LVMi was available in all patients as specified by the inclusion criteria. No patient had more than mild prosthetic or periprosthetic regurgitation. The average reduction in LVMi was $50 \pm 38 \mathrm{~g} / \mathrm{m}^{2}$. Late $\mathrm{LV}$ mass regression was unrelated to prosthesis type, size, or indexed prosthetic valve area by postoperative echocardiography (Table 3, Figure 1). The time to the echocardiogram was also not predictive of $\mathrm{LV}$ mass reduction $(P=.055)$. A greater preoperative LVMi $(P<.001)$ was the only independent predictor of greater LV mass regression. Despite the greatest

TABLE 1. Patient demographics

\begin{tabular}{|c|c|c|c|c|c|c|c|c|}
\hline Variable & $\begin{array}{c}\begin{array}{c}\text { Entire } \\
\text { cohort }\end{array} \\
(n=90)\end{array}$ & $\frac{\text { No PPM }}{(n=77)}$ & $\begin{array}{c}\text { PPM } \\
(n=13)\end{array}$ & $P$ value & $\begin{array}{c}\begin{array}{c}\text { Mildly } \\
\text { increased LVMi }\end{array} \\
(n=44)\end{array}$ & $\begin{array}{c}\begin{array}{c}\text { Moderately } \\
\text { increased LVMi }\end{array} \\
(\mathbf{n}=\mathbf{3 1})\end{array}$ & $\frac{\begin{array}{c}\text { Severely } \\
\text { increased LVMi }\end{array}}{(n=15)}$ & \\
\hline Age $(y)$ & $54.9 \pm 16.7$ & $56.0 \pm 16.9$ & $48.9 \pm 14.3$ & .124 & $54.9 \pm 16.0$ & $55.2 \pm 17.2$ & $54.5 \pm 18.6$ & .992 \\
\hline Female gender (no., \%) & $19(21.1)$ & $15(19.5)$ & $4(30.8)$ & .356 & $13(29.5)$ & $5(16.1)$ & $1(6.7)$ & .121 \\
\hline Hypertension (no., \%) & $41(45.6)$ & $33(42.9)$ & $8(61.5)$ & .211 & $20(45.5)$ & $15(48.4)$ & $6(40.0)$ & .267 \\
\hline Sinus rhythm (no., \%) & $76(84.4)$ & $65(84.4)$ & $11(84.6)$ & .932 & $39(88.6)$ & $24(77.4)$ & $14(93.3)$ & .866 \\
\hline NYHA class III or IV (no., \%) & $41(45.6)$ & $37(48.1)$ & $4(30.8)$ & .247 & $18(40.9)$ & $15(48.4)$ & $8(53.3)$ & .654 \\
\hline $\operatorname{BSA}\left(\mathrm{m}^{2}\right)$ & $2.0 \pm 0.2$ & $2.0 \pm 0.2$ & $2.3 \pm 0.3$ & .002 & $2.0 \pm 0.2$ & $2.1 \pm 0.3$ & $2.0 \pm 0.2$ & 275 \\
\hline Mean preoperative $\mathrm{EF}(\%)$ & $56 \pm 12$ & $56 \pm 12$ & $57 \pm 7$ & .780 & $60 \pm 9$ & $56 \pm 11$ & $47 \pm 15$ & $<.001$ \\
\hline Mean preoperative SWT (mm) & $11 \pm 2$ & $11 \pm 2$ & $12 \pm 2$ & .214 & $10 \pm 2$ & $12 \pm 2$ & $13 \pm 2$ & $<.001$ \\
\hline Mean preoperative PWT $(\mathrm{mm})$ & $11 \pm 2$ & $11 \pm 2$ & $11 \pm 2$ & .456 & $10 \pm 1$ & $11 \pm 2$ & $13 \pm 2$ & $<.001$ \\
\hline Mean preoperative LVEDD (mm) & $63 \pm 9$ & $64 \pm 9$ & $62 \pm 8$ & .687 & $59 \pm 5$ & $66 \pm 8$ & $72 \pm 8$ & $<.001$ \\
\hline Mean preoperative LVMi $\left(\mathrm{g} / \mathrm{m}^{2}\right)$ & $150 \pm 45$ & $161 \pm 45$ & $151 \pm 46$ & .451 & $126 \pm 15$ & $168 \pm 10.8$ & $241 \pm 34$ & $<.001$ \\
\hline
\end{tabular}

Continuous variables are expressed as mean \pm standard deviation. $B S A$, Body surface area; $E F$, ejection fraction; $L V E D D$, left ventricular end-diastolic dimension; $L V M i$, left ventricular mass index; NYHA, New York Heart Association; PPM, prosthesis-patient mismatch; $P W T$, posterior wall thickness; SWT, septal wall thickness. 
TABLE 2. Operative details

\begin{tabular}{|c|c|c|c|c|c|c|c|c|}
\hline Variable & $\begin{array}{c}\begin{array}{c}\text { Entire } \\
\text { Cohort }\end{array} \\
(n=90)\end{array}$ & $\frac{\text { No PPM }}{(n=77)}$ & $\frac{\text { PPM }}{(n=13)}$ & $P$ value & $\begin{array}{c}\text { Mild } \\
\text { increased LVMi } \\
(n=44)\end{array}$ & $\begin{array}{c}\begin{array}{c}\text { Moderate } \\
\text { increased LVMi }\end{array} \\
(n=31)\end{array}$ & $\begin{array}{c}\begin{array}{c}\text { Severe } \\
\text { increased LVMi }\end{array} \\
(n=15)\end{array}$ & $P$ value \\
\hline Mean CPB time (min) & $86 \pm 46$ & $87 \pm 46$ & $77 \pm 44$ & .438 & $91 \pm 39$ & $81 \pm 58$ & $81 \pm 35$ & .590 \\
\hline Mean crossclamp time (min) & $61 \pm 32$ & $63 \pm 32$ & $51 \pm 31$ & .210 & $65 \pm 32$ & $57 \pm 35$ & $58 \pm 24$ & .478 \\
\hline Median labeled valve size (mm) & 25 & 27 & 25 & .019 & 27 & 27 & 25 & .224 \\
\hline Mechanical valve (no., \%) & $25(27.8)$ & $25(32.3)$ & $0(0.0)$ & .016 & $12(27.3)$ & $9(29.0)$ & $4(26.7)$ & .981 \\
\hline Aortic root replacement $(\mathrm{N}, \%)$ & $20(22.2)$ & $19(24.6)$ & $1(7.7)$ & .727 & $12(27.3)$ & $3(9.7)$ & $5(33.3)$ & .263 \\
\hline Ascending aorta replacement $(\mathrm{N}, \%)$ & $3(3.3)$ & $3(3.9)$ & $0(0.0)$ & & $2(4.5)$ & $1(3.2)$ & $0(0)$ & \\
\hline
\end{tabular}

Continuous variables are expressed as mean \pm standard deviation. $C P B$, Cardiopulmonary bypass; $L V M i$, left ventricular mass index; $P P M$, prosthesis-patient mismatch.

LV mass regression, patients with severe preoperative LVMi did not return to normal late LVMi measurements (mean, $142 \pm 25 \mathrm{~g} / \mathrm{m}^{2}$ ).

Univariate predictors of return to normal late LVMi (LV mass $<100 \mathrm{~g} / \mathrm{m}^{2}$ ) included female gender (OR, 3.5; $P=.022)$, higher preoperative ejection fraction (OR, 1.1 per $1 \% ; P=.010$ ), smaller interventricular septal thickness (OR, 0.8 per $1 \mathrm{~mm} ; P=.028$ ), smaller posterior wall thickness (OR, 0.7 per $1 \mathrm{~mm} ; P=.005)$, smaller LV end-diastolic dimensions (OR, 0.9 per $1 \mathrm{~mm} ; P=.002$ ), smaller LV endsystolic dimensions (OR, 0.9 per $1 \mathrm{~mm} ; P=.002)$, and a smaller preoperative LVMi (OR, 0.9 per $1 \mathrm{~g} / \mathrm{m}^{2}$; $P<.001)$ was predictive of late return to normal LVMi. The time from the late measurement of LVMi and surgery

TABLE 3. Univariate predictors of $L V$ mass regression after AVR for chronic AR

\begin{tabular}{lc}
\hline & $\begin{array}{c}\text { Univariate } \\
\boldsymbol{P} \text { value }\end{array}$ \\
\hline Clinical variables & \\
Younger age & .115 \\
Smaller BSA & .092 \\
Male gender & .405 \\
Year of operation & .408 \\
Absence of hypertension & .747 \\
NYHA class & .727 \\
Valve size & .718 \\
Echocardiographic variables & \\
Larger preoperative SWT & $<.001$ \\
Larger preoperative PWT & $<.001$ \\
Larger preoperative LVEDD & $<.001$ \\
Larger preoperative LVMi & $<.001$ \\
Larger preoperative LVESD & .007 \\
Lower preoperative ejection fraction & .357 \\
Time between follow-up & .547 \\
$\quad$ echocardiography and operation & \\
Lower postoperative mean aortic valve gradient & .583 \\
Smaller postoperative indexed aortic valve area & .891 \\
\hline$A R$, Aortic valve regurgitation; $A V R$, aortic valve replacement; $B S A$, body surface \\
area; $L V$, left ventricular; $L V E D D$, left ventricular end-diastolic dimension; $L V E S D$, \\
left ventricular end-systolic dimension; $L V M i$, indexed left ventricular mass; \\
$N Y H A$, New York Heart Association; $P W T$, posterior wall thickness; $S W T$, septal \\
wall thickness.
\end{tabular}

date was not associated with late normal LVMi $(P=$ .928). After adjusting for age and gender, the only independent association with late normal LVMi was a smaller preoperative LVMi $\left(\mathrm{OR}, 1.0\right.$ per $\left.1 \mathrm{~g} / \mathrm{m}^{2} ; P<.001\right)$.

Neither the presence of PPM $(P=.893)$ nor the indexed aortic valve area $(P=.887)$ was predictive of late return to normal LVMi. Patients with the largest valve sizes (27, 29, and $31 \mathrm{~mm}$ ) were more likely to have a late normal LVMi when compared with the smallest valve size $(21 \mathrm{~mm})$ (OR, 0.2; $P=.044$ ), but there was no difference between valve sizes (23 and $25 \mathrm{~mm})$ and the smallest valve size $(21 \mathrm{~mm})(\mathrm{OR}, 0.2 ; P=.081)$.

\section{DISCUSSION}

In this study, the extent of LV mass regression was not related to valve type, valve size, indexed effective prosthetic valve area, prosthetic valve gradient, or PPM. Indeed, the only significant predictor of extent of LV mass regression was degree of LV hypertrophy preoperatively. We were careful to select patients who had pure aortic valve regurgitation, and we were careful to exclude concomitant diagnoses that might independently influence LV mass, such as moderate or more aortic valve stenosis, greater than moderate mitral valve regurgitation, and known coronary artery disease.

There are few published data that specifically address the potential problem of PPM and surgery for AR. PPM was uncommon (14\%) in our patients undergoing AVR for chronic AR. Our findings are similar to results of Price and associates, ${ }^{14}$ who reported that the incidence of PPM in patients undergoing valve replacement for AR was half that of patients operated on for aortic valve stenosis, and this is likely due to the concomitant enlargement of the aortic root in patients with AR. In our larger cohort of patients with AR, which was previously published, ${ }^{15} 22 \%$ of patients had PPM. PPM is more common in cohorts mainly composed of patients with aortic stenosis: $33 \%$ of patients having AVR in a Canadian study ${ }^{7}$ and $62 \%$ in a study from $\mathrm{St}$ Louis. $^{16}$

We did not assess the effect of PPM on mortality owing to the limited number of patients with PPM. Nevertheless, in our larger cohort of patients with $\mathrm{AR}$ and $\mathrm{AVR},{ }^{15}$ the 

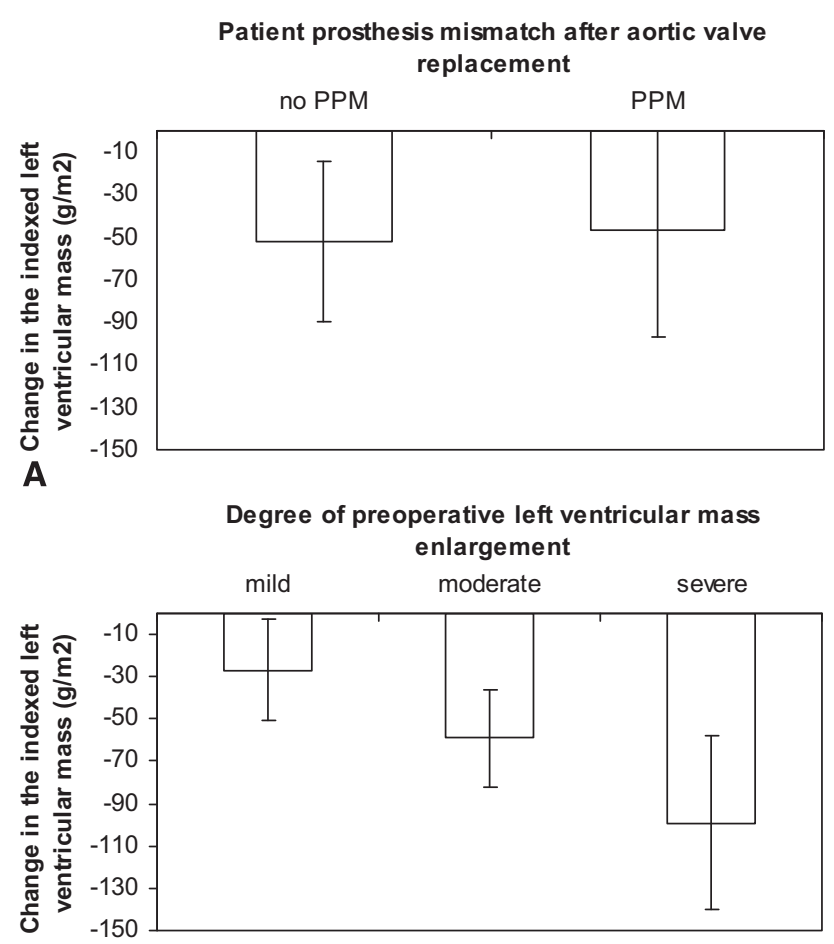

B

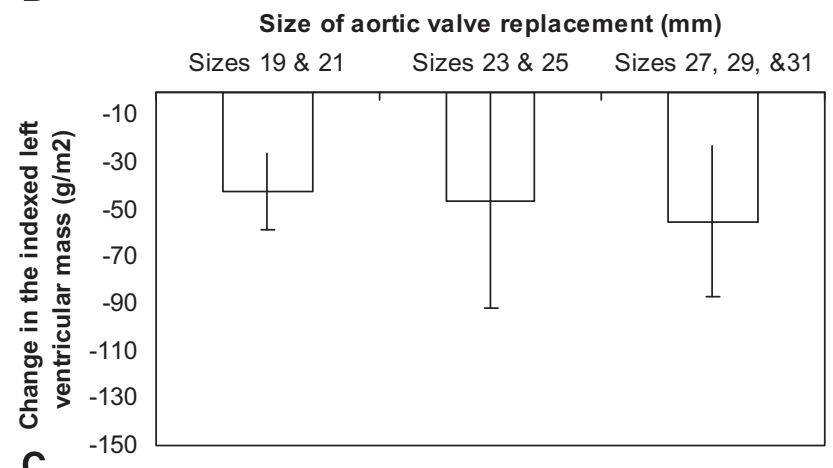

FIGURE 1. The average change in LV mass from preoperative to late after AVR for chronic AR is stratified into PPM, preoperative LVMi, and labeled valve sizes. All data are expressed as means and error bars represent standard deviations. A, Presence or absence of PPM (indexed effective aortic valve area $<0.85 \mathrm{~cm}^{2} / \mathrm{m}^{2}$ ). There was no statistically significant difference $(P=.788)$. B, Mild, moderate, or severely enlarged preoperative LVMi. There was a statistically significant difference in the degree of LV mass regression in these groups $(P<.001)$. C, Grouped by valve sizes. There was no statistically significant difference $(P=.439) . L V$, Left ventricular; $A V R$, aortic valve replacement; $A R$, aortic valve regurgitation; $P P M$, patientprosthesis mismatch; $L V M i$, indexed left ventricular mass.

indexed effective aortic valve area was not a predictor of overall mortality (unpublished data). Our current study differs from our previous manuscript, inasmuch as it specifically focuses on predictors of LV remodeling.

Price and coworkers ${ }^{14}$ found a trend toward less mass regression in patients who had PPM after AVR for AR (difference in indexed LV mass, $30 \pm 17 \mathrm{~g} / \mathrm{m}^{2} ; P=.07$ ), although they suggested that their study may have been underpowered. In our analysis, the only independent predictor of extent of LV mass regression was a larger preoperative LV mass. However, regression of hypertrophy was not complete in those with the largest preoperative LVMi. Other studies have shown that although LV mass regression occurs after valve replacement for AR, it is incomplete in most patients. ${ }^{17-20}$ In the study from Taniguchi and colleagues $^{20}$ of 82 patients with AVR for AR, regression of LV hypertrophy was limited in patients with an LVMi of more than $200 \%$ of normal. Taniguchi assumed that there were no cases of PPM (effective orifice area index $>0.9$ $\mathrm{cm}^{2} / \mathrm{m}^{2}$ ). In contrast, our results suggest that very large ventricles can undergo reverse remodeling.

A smaller preoperative LVMi was the only independent predictor of late normal LVMi. Other univariate associations with normal LVMi included gender (women tend to have smaller LV mass) and higher ejection fractions. Indexed aortic valve area and the presence of PPM were not related to late normal LVMi in our study. The consequences of incomplete regression are unknown, but in patients with isolated hypertensive heart disease, greater LV mass has been identified as a risk factor for mortality and cardiovascular events, including stroke and coronary artery disease. $^{21-23}$

There are several methods to calculate prosthetic valve "size." ${ }^{24}$ The labeled valve size (in millimeters) refers to the diameter of the external sewing ring in mechanical prostheses and the diameter of the mounting ring in stented bioprostheses. Using the formula of a circle, the valve area can be calculated using these measurements. Valve manufacturers also provide calculated internal geometric orifice areas that provide an in vitro measurement. In our study, however, we used in vivo measurements of indexed aortic valve area calculated early after operation on transthoracic echocardiography. This provides a more realistic estimate of the valve area. Indexed aortic valve area has been shown to predict mismatch as well as resting and exercise postoperative gradients. ${ }^{25}$

A limitation of our study is that we do not have follow-up echocardiography available on all patients at a consistent interval. Although recommended in clinical practice, echocardiograms may not be available for our review or may not be done as suggested. Many patients are not followed up at Mayo Clinic. Our study may also have been underpowered to detect some differences between patient groups, as we had only 13 patients with PPM in our cohort. Finally, this analysis was not designed to determine whether PPM affects survival, inasmuch as our inclusion criteria required that a patient had available follow-up echocardiography.

\section{References}

1. Pibarot P, Dumesnil JG. Prosthesis-patient mismatch: definition, clinical impact, and prevention. Heart. 2006;92:1022-9. 
2. Walther T, Rastan A, Falk V, Lehmann S, Garbade J, Funkat AK, et al. Patient prosthesis mismatch affects short-and long-term outcomes after aortic valve replacement. Eur J Cardiothorac Surg. 2006;30:15-9.

3. Mohty D, Malouf JF, Girard SE, Schaff HV, Grill DE, Enriquez-Sarano ME, et al. Impact of prosthesis-patient mismatch on long-term survival in patients with small St Jude Medical mechanical prostheses in the aortic position. Circulation. 2006;113:420-6.

4. Moon MR, Pasque MK, Munfakh NA, Melby SJ, Lawton JS, Moazami N, et al. Prosthesis-patient mismatch after aortic valve replacement: impact of age and body size on late survival. Ann Thorac Surg. 2006;81:481-8.

5. Blais C, Dumesnil JG, Baillot R, Simard S, Doyle D, Pibarot P. Impact of prosthesis-patient mismatch on short-term mortality after aortic valve replacement. Circulation. 2003;108:983-8.

6. Tasca G, Mhagna Z, Perotti S, Centurini PB, Sabatini T, Amaducci A, et al. Impact of prosthesis-patient mismatch on cardiac events and midterm mortality after aortic valve replacement in patients with pure aortic stenosis. Circulation. 2006;113:570-6.

7. Mohty D, Dumesnil JG, Echahidi N, Mathieu P, Dagenais F, Voisine P, et al. Impact of prosthesis-patient mismatch on long-term survival after aortic valve replacement. J Am Coll Cardiol. 2009;53:39-47.

8. Blackstone EH, Cosgrove DM, Jamieson WR, Birkmeyer NJ, Lemmer JH Jr, Miller DC, et al. Prosthesis size and long-term survival after aortic valve replacement. J Thorac Cardiovasc Surg. 2003;126:783-93.

9. Howell NJ, Keogh BE, Barnet V, Bonser RS, Graham TR, Rooney SJ, et al. Patient-prosthesis mismatch does not affect survival following aortic valve replacement. Eur J Cardiothorac Surg. 2006;30:10-4.

10. Koch CG, Khandwala F, Estafanous FG, Loop FD, Blackstone EH. Impact of prosthesis-patient size on functional recovery after aortic valve replacement. Circulation. 2005;111:3221-9.

11. Monin JL, Monchi M, Kirsch ME, Petit-Eisenmann H, Baleynaud S, Chauvel C, et al. Low-gradient aortic stenosis: impact of prosthesis-patient mismatch on survival. Eur Heart J. 2007;28:2620-6.

12. Flameng W, Meuris B, Herijgers P, Herregods MC. Prosthesis-patient mismatch is not clinically relevant in aortic valve replacement using the CarpentierEdwards Perimount valve. Ann Thorac Surg. 2006;82:530-6.

13. Lang RM, Bierig M, Devereux RB, Flachskampf FA, Foster E, Pellikka PA, et al. American Society of Echocardiography's Nomenclature and Standards Committee; Task Force on Chamber Quantification; American College of Cardiology Echocardiography Committee; American Heart Association; European Association of Echocardiography, European Society of Cardiology. Recommendations for chamber quantification. Eur J Echocardiogr. 2006;7:79-108.

14. Price J, Chan V, Klulik A, Ressler L, Bedard P, Mesana TG, et al. Differen incidence and implications of prosthesis-patient mismatch after aortic valve replacement for aortic insufficiency versus aortic stenosis. Available at: www. pulsus.com/ccc2007/abs/0396.htm. Accessed on May 20, 2009.

15. Brown ML, Schaff HV, Suri RM, Li Z, Sundt TM, Dearani JA, et al. Indexed left ventricular dimensions best predict survival after aortic valve replacement in patients with aortic valve regurgitation. Ann Thorac Surg. 2009;87:1170-5.

16. Moon MR, Lawton JS, Moazami N, Munfakh NA, Pasque MK, Damiano RJ Jr POINT: Prosthesis-patient mismatch does not affect survival for patients greater than 70 years of age undergoing bioprosthetic aortic valve replacement. J Thorac Cardiovasc Surg. 2009;137:278-83.

17. Taniguchi K, Nakano S, Kawashima Y, Sakai K, Kawamoto T, Sakaki S, et al. Left ventricular ejection performance, wall stress, and contractile state in aortic regurgitation before and after aortic valve replacement. Circulation. 1990;82:798-807.

18. Roman MJ, Klein L, Devereux RB, Kligfield P, Niles NW, Hochreiter C, et al. Reversal of left ventricular dilatation, hypertrophy, and dysfunction by valve replacement in aortic regurgitation. Am Heart J. 1989;118:553-63.

19. Tasca G, Brunelli F, Cirillo M, DallaTomba M, Mhagna Z, Troise G, et al. Impact of valve prosthesis-patient mismatch on left ventricular mass regression following aortic valve replacement. Ann Thorac Surg. 2005;79:505-10.

20. Taniguchi K, Takahashi T, Toda K, Matsue H, Shudo Y, Shintani H, et al. Lef ventricular mass: impact on left ventricular contractile function and its reversibility in patients undergoing aortic valve replacement. Eur J Cardiothorac Surg. 2007;32:588-95.

21. Kahan T. The importance of left ventricular hypertrophy in human hypertension. J Hypertens. 1998;16:S23-9.

22. Koren MJ, Devereux RB, Casale PN, Savage DD, Laragh JH. Relation of lef ventricular mass and geometry to morbidity and mortality in uncomplicated essential hypertension. Ann Intern Med. 1991;114:345-52.

23. Levy D, Garrison RJ, Savage DD, Kannel WB, Castelli WP. Prognostic implications of echocardiographically determined left ventricular mass in the Framingham Heart Study. N Engl J Med. 1990;322:1561-6.

24. Gillinov AM, Blackstone EH, Rodriguez LL. Prosthesis-patient size: measurement and clinical implications. J Thorac Cardiovasc Surg. 2004;126:313-6.

25. Pibarot P, Dumesnil JG, Cartier PC, Metras J, Lemieux MD. Patient-prosthesis mismatch can be predicted at the time of operation. Ann Thorac Surg. 2001 71:S265-8. 